\title{
Evaluation of Therapeutic Efficacy of Trimethoprim-sulphamethoxazole* and Chloramphenicol in Enteric Fever
}

\author{
S. A. KAMAT, $†$ M.D.
}

British Medical fournal, 1970, 3, 320-322

\begin{abstract}
Summary: In a clinical trial on 220 patients with bacteriologically proved enteric fever trimethoprimsulphamethoxazole was compared with. chloramphenicol. All patients in both groups responded, and the mean periods of defervescence after starting therapy were similar in both groups. Trimethoprim-sulphamethoxazole was much superior to chloramphenicol in rapidity and uniformity of relief of toxaemia. "Toxic crisis" occurred in 10 out of 120 patients in the chloramphenicol group and was absent in the trimethoprim-sulphamethoxazole group. No major side-effects due to specific drug therapy were observed in either group.
\end{abstract}

\section{Introduction}

For two decades chloramphenicol has been accepted as the drug of choice in the oral treatment of enteric fever (Robertson et al., 1968). Nevertheless, its use in the treatment of enteric fever has many disadvantages. The number of days taken for the temperature to return to normal-defervescence-after starting treatment with chloramphenicol has been increasing progressively over the years-3.5 days in 1948 (Woodward et al., 1948), 4.1 days in 1962 (Huckstep, 1962), and 5.1 days in 1967 (Kamat et al., 1968). Chakraborty (1961) noted that between 1956 and 1960 the average defervescence period after chloramphenicol increased from 3.5 to 6.2 days, showing a gradual yearly increase. The features of typhoid toxaemia such as headache, restlessness, lassitude, apathy, drowsiness, anorexia, mental disorientation, hyperexcitability or delirium, involuntary movements, and tachycardia sometimes persist even when the patient becomes afebrile. "Toxic crisis"-an apparently drug-induced exacerbation of toxaemia that sometimes occurs early in the course of treatment (Marmion, 1952)-is an ever-present danger in treatment of enteric fever with chloramphenicol (Marmion, 1952; Kamat, 1969).

In chloramphenicol-treated cases relapses are more common than in untreated cases (Huckstep, 1962), and carriers remain unaffected (Cluff, 1963). Chloramphenicol has been said to be the leading cause of drug-induced aplastic anaemia (New England fournal of Medicine, 1967). Its leukaemogenic effects have now been recognized (Brauer and Dameshek, 1967). These drawbacks of chloramphenicol therapy have led many workers in this field to look for safer and more effective remedies. Thus ampicillin (Sanders, 1965; Robertson et al., 1968), niridazole (Kamat et al., 1968), and furazolidone (Omar and Wahab, 1967; Kamat, 1968a) have been evaluated against chloramphenicol, but none of these drugs have been found to be therapeutically superior to chloramphenicol.

If a new drug is to achieve a status comparable or superior to chloramphenicol in the treatment of enteric fever it must prove to be as effective and possibly to possess a greater margin of safety. Clinical trials in different regions of the world have shown that trimethoprim-sulphamethoxazole is effective in the treatment of enteric fever (Akinkugbe et al., 1968; Kamat, 1969; Kamat et al., 1969; Semprevivo et al., 1969), notable features being the absence of "toxic crisis" and

\footnotetext{
Each tablet of trimethoprim-sulphamethoxazole contained $80 \mathrm{mg}$. of

trimethoprim and $400 \mathrm{mg}$. of sulphamethozazole.
t Honorary Assistant Professor, Grant Medical College; Honorary Assis-
tant Physician, G.T. Hospital and Kasturba Hospital for Infectious tant Physician, G.T. Hospital and Kasturba Hospital for Infectious Diseases, Bombay.
}

uniformity and rapidity in the relief of toxaemia. In a small comparative trial patients treated with trimethoprimsulphamethoxazole were found to respond more rapidly than those treated with chloramphenicol (Akinkugbe et al., 1968).

The present trial was undertaken to compare trimethoprim-sulphamethoxazole with chloramphenicol in the treatment of enteric fever, with particular reference to therapeutic efficacy and safety.

\section{Patients and Methods}

The trial was conducted at the Kasturba Hospital for Infectious Diseases, Bombay, from May to October 1969. For better control of the trial and follow-up the study was restricted to adult male inpatients. Patients suspected clinically to be suffering from enteric fever were allocated randomly to two groups, one to be treated with trimethoprim-sulphamethoxazole and the other with chloramphenicol. Before starting specific therapy samples were taken for the following investigations : routine urine examination, routine blood picture, blood clot culture for salmonellae, and Widal reaction.

Specific treatment was started without awaiting the results of these investigations. Though stools were collected for culture for salmonellae the first specimens in patients who were constipated were not obtainable until a day or two after admission-that is, after specific therapy was started-thus making the value of this investigation questionable. Intravenous fluids were given when indicated. No other specific therapy was given. Patients were examined daily to record progress and to detect side-effects or toxic reactions of specific therapy. A Widal test was carried out every fourth day.

Out of a total of 900 cases of clinically suspected enteric fever, blood clot cultures were positive for salmonellae in 220 (Salmonella typhi in 212 and S. paratyphi A in 8). Only these 220 patients with bacteriologically proved enteric fever were studied-100 belonged to the group treated with trimethoprim-sulphamethoxazole and 120 formed the control group treated with chloramphenicol.

Patients were kept under observation in hospital for at least 15 days after defervescence. Owing to shortage of beds the stay in hospital of patients in the trial could not be extended. After treatment and before discharge from hospital clot culture was repeated in each case and stool culture for salmonellae was carried out.

After discharge patients are being followed up, and periodical clinical and bacteriological examinations will be made for one year. The results of this follow-up to determine relapses, long-term complications, long-term drug toxicity, and incidence of carrier rate after treatment with trimethoprimsulphamethoxazole and chloramphenicol will be reported later.

\section{Dosage Schedules}

Trimethoprim-Sulphamethoxazole.-Early in the trial the dose given was three tablets twice a day till defervescence, followed by two tablets twice a day for seven days. As the response was excellent it was decided to study in a few patients the efficacy of the standard dose for other infections-that is, 
two tablets twice a day. Response to two tablets twice daily was as good as with three tablets twice daily, and for the rest of the trial the dosage schedule was two tablets twice daily for seven days after defervescence. In the final analysis it was found that 50 patients received three tablets twice a day and 50 received two tablets twice a day. Response to treatment with these dosage schedules was so similar that for the purpose of analysis the 100 patients treated with trimethoprimsulphamethoxazole have been considered a homogeneous group.

Chloramphenicol.-The routine hospital schedule was used - that is, $500 \mathrm{mg}$. six-hourly till defervescence followed by $500 \mathrm{mg}$. eight-hourly for four days, $500 \mathrm{mg}$. 12-hourly for four days, and $250 \mathrm{mg}$. eight-hourly for four days.

\section{Clinical Details}

The ages of the patients in the two treatment groups on admission are shown in Table $I$. The youngest and oldest were aged 12 and 65 . The duration of fever before admission is shown in Table II. The longest and shortest durations of fever before institution of therapy with trimethoprimsulphamethoxazole were 15 and 2 days respectively and in the chloramphenicol-treated group 30 days and 1 day respectively. Toxaemia was present on admission in 17 of the 100 patients in the trimethoprim-sulphamethoxazole group and in 32 of the 120 in the chloramphenicol group. The temperature on admission is shown in Table III.

TABLE I.-Age Groups of Patients

\begin{tabular}{|c|c|c|c|c|}
\hline \multirow{2}{*}{\multicolumn{3}{|c|}{ Age }} & \multicolumn{2}{|l|}{ No. of Patients } \\
\hline & & & $\begin{array}{l}\text { Trimethoprim-Sulphamethoxazole } \\
\text { Group }\end{array}$ & $\begin{array}{l}\text { Chloramphenicol } \\
\text { Group }\end{array}$ \\
\hline $\begin{array}{l}10-19 \text { Years } \\
20-29 \text { "3 } \\
30-39 \\
40+\text { Years }\end{array}$ & $\begin{array}{l}\ldots \\
\cdots \\
\cdots\end{array}$ & $\begin{array}{l}\because \\
\because \\
.\end{array}$ & $\begin{array}{r}30 \\
53 \\
14 \\
3\end{array}$ & $\begin{array}{r}30 \\
71 \\
12 \\
7\end{array}$ \\
\hline
\end{tabular}

TABLE II.-Duration of Fever before Admission

\begin{tabular}{|c|c|c|c|c|}
\hline \multirow{2}{*}{\multicolumn{3}{|c|}{$\begin{array}{l}\text { Duration of Fever } \\
\text { before Treatment }\end{array}$}} & \multicolumn{2}{|l|}{ No. of Patients } \\
\hline & & & \multirow{2}{*}{$\begin{array}{c}\begin{array}{c}\text { Trimethoprim-Sulphamethoxazole } \\
\text { Group }\end{array} \\
15 \\
40 \\
30 \\
11 \\
4\end{array}$} & \multirow{2}{*}{\begin{tabular}{|c|}
$\begin{array}{c}\text { Chloramphenicol } \\
\text { Group }\end{array}$ \\
19 \\
48 \\
27 \\
13 \\
13 \\
\end{tabular}} \\
\hline $\begin{array}{c}1-3 \text { days } \\
4-6 \text { " } \\
7-9 \text { " } \\
10-12 \text { "3 } \\
12+\text { days }\end{array}$ & $\begin{array}{l}\cdots \\
\cdots \\
\cdots\end{array}$ & $\begin{array}{l}\ldots \\
\cdots \\
\cdots\end{array}$ & & \\
\hline
\end{tabular}

The mean duration of $f$ ever before admission was 6.6 days in the trimethoprimsulphamethoxazole grou p and 7.3 days in the chloramphenicol group.

TABLE III.-Temperature on Admission

\begin{tabular}{|c|c|c|}
\hline $\begin{array}{c}\text { Axillary } \\
\text { Temperature }\end{array}$ & $\begin{array}{c}\text { Trimethoprim-Sulphamethoxazole } \\
\text { Group }\end{array}$ & $\begin{array}{l}\text { Chloramphenicol } \\
\text { Group }\end{array}$ \\
\hline $\begin{array}{l}\text { Below } 100^{\circ} \mathrm{F} .\left(37 \cdot 8^{\circ} \mathrm{C} .\right) \\
100 \text { to } 102^{\circ} \mathrm{F} . \quad\left(38^{\circ} 9^{\circ} \mathrm{C} \text {.) }\right.\end{array}$ & $\begin{array}{l}33 \\
31 \\
66\end{array}$ & $\begin{array}{r}2 \\
32 \\
86\end{array}$ \\
\hline
\end{tabular}

With regard to age, duration of fever before admission, toxaemia on admission, and temperature on admission there seems to be no significant statistical difference between the trimethoprim-sulphamethoxazole group and the chloramphenicol group.

\section{Results}

Response to Treatment.-The response of fever to treatment is shown in Table IV. The longest and shortest periods for defervescence in the trimethoprim-sulphamethoxazole group were one day and eight days respectively, and in the chloramphenicol group two and eight days respectively. All patients in both groups became afebrile with treatment. The response of toxaemia to treatment is shown in Table $\mathrm{V}$. After completion of treatment pronounced weakness persisted for about one week in the trimethoprim-sulphamethoxazole group and for two to three weeks in the chloramphenicol group.

Complications.-Ten patients in the chloramphenicol group developed "toxic crisis" which necessitated appropriate treatment. No patient developed "toxic crisis" in the trimethoprim-sulphamethoxazole group. Other serious complications, such as haemorrhage and perforation, were not seen in either treatment group.

Adverse Reactions.-These are shown in Table VI. One patient, who was among the 900 patients in this trial but did not belong to the groups analysed as his blood culture was

\begin{tabular}{cccc|c|c}
\multicolumn{6}{c}{ TABLE IV.-Response of Fever to Treatment } \\
\hline \multicolumn{2}{c|}{$\begin{array}{c}\text { No. of Days Taken } \\
\text { for Temperature to } \\
\text { Return to Normal } \\
\text { (Defervescence) }\end{array}$} & \multicolumn{3}{|c}{ No. of Patients } \\
\cline { 2 - 5 } & $\begin{array}{c}\text { Trimethoprim-Sulphamethoxazole } \\
\text { Group }\end{array}$ & $\begin{array}{c}\text { Chloramphenicol } \\
\text { Group }\end{array}$ \\
\hline $1-3$ & $\ldots$ & $\ldots$ & $\ldots$ & 41 & 41 \\
$4-6$ & $\ldots$ & $\ldots$ & $\cdots$ & 55 & 66 \\
$7-9$ & $\cdots$ & $\cdots$ & $\cdots$ & 4 & 13 \\
\hline
\end{tabular}

The mean period of defervescence in the trimethoprim-sulphamethoxazole group was 4 days and in the chloramphenicol group $4 \cdot 3$ days.

TABLE V.-Response of Toxaemia to Treatment

\begin{tabular}{|c|c|}
\hline $\begin{array}{c}\text { Trimethoprim-Sulphamethoxazole } \\
\text { Group }\end{array}$ & $\begin{array}{l}\text { Chloramphenicol } \\
\text { Group }\end{array}$ \\
\hline $\begin{array}{l}\text { Of } 17 \text { patients who were toxaemic on } \\
\text { admission in this group, toxaemia was } \\
\text { completely relieved by the 3rd day in } \\
15 \text { and by the } 4 \text { th day in } 2 \text {. } \\
\text { No patient who was non-toxaemic on } \\
\text { admission developed toxaemia after } \\
\text { starting trimethoprim-sulphamethoxa- } \\
\text { zole therapy. }\end{array}$ & $\begin{array}{l}\text { In addition to the } 32 \text { patients who were } \\
\text { toxaemic on admission a further } 11 \\
\text { not toxaemic on admission developed } \\
\text { toxaemia after starting chloram- } \\
\text { phenicol. } 19 \text { patients were free of } \\
\text { toxaemia by the 3rd day. In the } \\
\text { remainder toxaemia was relieved } \\
\text { after a variable period of up to } 7 \\
\text { days. }\end{array}$ \\
\hline $\begin{array}{l}\text { Toxaemia did not worsen in any patient } \\
\text { after starting trimethoprim-sulphame- } \\
\text { thoxazole. }\end{array}$ & $\begin{array}{l}\text { In } 10 \text { patients toxaemia worsened after } \\
\text { starting chloramphenicol; they went } \\
\text { into a "toxic crisis" which neces- } \\
\text { sitated treatment. }\end{array}$ \\
\hline
\end{tabular}

TABLE VI.-Adverse Reactions

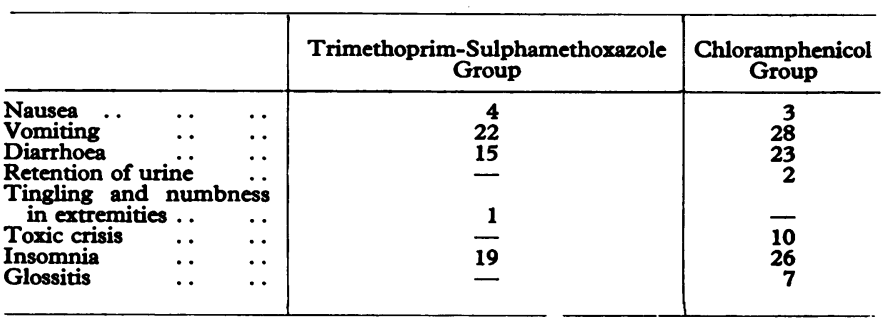

negative, developed thrombocytopenic purpura while on treatment with trimethoprim-sulphamethoxazole. $F$ : recovered on withdrawal of the drug and with appropriate $s$ pportive treatment. This case will be reported separately.

\section{Discussion}

Selection of Patients.-To avoid controversy about the diagnosis of enteric fever we studied only those patients with a blood clot culture positive for salmonellae. When blood clot culture was negative for salmonellae we did not rely on investigations which are not definitive in the diagnosis of enteric fever. The Widal reaction cannot be accepted as an absolute diagnostic criterion (Kostic, 1963), for it may never become positive throughout the course of the disease (Singh and Saxena, 1964) and may actually show a static or even a 
falling titre. Rising Widal titres were detected in less than half the patients (Kamat et al., 1968). Isolation of salmonellae from stool culture is not a completely reliable criterion in making a definitive diagnosis of enteric fever. Carriers (excreters of salmonellae in stools) suffering from other fevers may be misdiagnosed as having acute enteric fever if diagnosis is based on a positive stool culture in the absence of a positive blood culture (Manson-Bahr, 1966). The low rate of isolation of salmonellae from blood clot culture in our series ( 1 in 4) may be explained partly because only a single clot culture was done before treatment, and partly because many patients reported to the hospital late during the disease (after a mean period of seven days of fever).

Comparability of Trimethoprim-Sulphamethoxazole and Chloramphenicol Groups before Treatment.-There was no significant difference in ages or duration of fever in the two treatment groups before admission. The temperatures in the two groups on admission were not significantly different. There may, however, have been a difference in the proportions showing toxaemia $(0.05<\mathrm{P}<0.1)$. Thus there was virtually no difference between the two groups before treatment.

Response to Treatment.-In both groups the response to therapy was good and there were no treatment failures. The rapidity of response of fever to treatment in both groups was similar, average defervescence occurring in 4.0 days in the trimethoprim-sulphamethoxazole group and 4.3 days in the chloramphenicol group. Response of toxaemia to treatment, however, was different in the two groups. All patients admitted with toxaemia in the trimethoprim-sulphamethoxazole group responded favourably, a daily improvement in toxaemia being noticeable and most of them (88\%) were free of toxaemia within three days and all in four days. In comparison only $40 \%$ of patients admitted with toxaemia in the chloramphenicol group were free of toxaemia by the third day, the rest remaining toxaemic for up to seven days. This is statistically significant. No patient who was non-toxaemic on admission in the trimethoprim-sulphamethoxazole group developed toxaemia after starting treatment with this drug, while in the chloramphenicol group 11 patients who were non-toxaemic on admission developed toxaemia after starting treatment with chloramphenicol. This is highly significant $(\mathrm{P}<0.001)$.

Complications.- "Toxic crisis" did not occur in the trimethoprim-sulphamethoxazole group, but 10 patients in the chloramphenicol group developed "toxic crisis"; this is highly significant. Complications such as perforation and haemorrhage were not seen in either group during the period in hospital. The absence of haemorrhage and perforation in our series may surprise many workers from other parts of the world. These results however, were not surprising in Bombay as low complication rates are usual there (Kalra et. al., 1968; Padmanabhan, 1968; Kamat, 1968a, 1968b, 1969; Kamat et al.. 1968, 1969). Even in the prechloramphenicol era, enteric fever in South India had a low rate of perforation and mortality (Dunkerley, 1946). Perhaps differences in strains of the invading organism, resistance of the host dependent on ethnic and geographical differences, and promptness of specific therapy after onset of symptoms explain the differences in incidence of serious complications in different parts of the world.
Adverse Reactions.-Nausea, vomiting, diarrhoea, and insomnia were fairly common in both groups, the difference in the frequency of occurrence not being statistically significant. Since these are also symptoms of enteric fever itself it is difficult to determine whether they were caused by the disease or by the drug administered. Retention of urine occurred in two patients in the chloramphenicol group, but since enteric fever itself can cause this we cannot definitely say that chloramphenicol was responsible. Similarly, the occurrence of paraesthesiae, which was noted in one patient in the trimethoprim-sulphamethoxazole group, cannot be definitely ascribed to the drug.

The incidence of "toxic crisis," appearance of toxaemic. after starting treatment, and glossitis in 10,11, and 7 patients respectively in the chloramphenicol group, and the absence of these adverse reactions in the trimethoprimsulphamethoxazole group are highly significant. Pronounced weakness and even prostration were notable features in the chloramphenicol group, weakness often persisting for two to three weeks after completion of treatment. By comparison, in the trimethoprim-sulphamethoxazole group weakness was short-lived, lasting up to about a week after completion of therapy.

Blood urea, serum bilirubin, and peripheral blood pictures after completion of treatment with trimethoprimsulphamethoxazole in $10 \%$ of randomly chosen patients did not show abnormalities.

I thank Messrs. Burroughs Wellcome (India) Private Ltd. for the generous supply of tablets of trimethoprim-sulphamethoxazole for the trial, and the resident and nursing staff of the Kasturba Hospital for Infectious Diseases for their help and co-operation.

\section{REFERENCES}

Akinkugbe, O. O., Lewis, E. A., Montefiore, D., and Okubadejo, O. A (1968). British Medical fournal, 3, 721 .

Brauer, M. J., and Dameshek, W.' (1967). New England fournal of Medicine, 277, 1003

British Medical fournal, 1969, 3, 605.

Chakraborty, G. (1961). Indian fournal of Pediatrics, 28, 365.

Cluff. L. E. (1963). In Coril-Loeb Textbook of Mericine, ed. P. B. Beeson and W. McDermott, 11th edn., p. 235. Philadelphia Saunders.

Dunkerley, G. E. (1946). British Medical fournal, 2, 454

Huckstep, R. L. (1962). Typhoid Fever and Other Salmonella Infections, pp. 57, 147. Edinburgh, Livingstone.

Kalra, K., et al. (1968). Proceedings of the 1st National Conference in Infectious Diseases in Bombay. In press.

Kamat, S. A. (1968a). Fournal of the American Medical Association, 206, 2745 .

Kamat, S. A. (1968b). Proceedings of the National Conference in Infectious Diseases at Bombay. In press.

Kamat, S. A. (1969). Proceedings of the 6th International Congress in Chemotherapy, Tokyo. In press.

Kamat, S. A., et al. (1968). Proceedings of the 8th International Congress in Tropical Medicine and Malaria, Teheran. In press.

Kamat, S. A., Bamii, D. D., Deshpande, R. S., and Patel, L. R. (1969). Indian Practitioner, 22. 403.

Kostic, A. (1963). Presse Médicale, 71, 2489.

Manson-Bahr, P. (1966). Manson's Tropical Diseases, 16th edn., p. 271 London, Baillière, Tindall \& Cassell.

Marmion. D. E. (1952). Transactions of the Royal Society of Tropical Medicine and Hvgiene, 46, 619.

New England fournal of Medicine, 1967, 277, 1035.

Omar, M. E. S., and Wahab, M. F. A. (1967). fournal of Tropical Medicine and Huriene, 70. 43 .
M.

Padmanabhan, $\mathrm{K}$. (1968). Proceedings of the 1st National Conference in Infectious Diseases in Bombay. In press.

Robertson, R. P., Wahab, M. F. A., and Raasch, F. O. (1968). New England fournal of Medicine, 278. 171.

Sanders, W. L. (1965). British Medical fournal, 2. 1226.

Semprevivo, L., et al. (1969). Proceedings of the 6th International Congress in Chemotherapy, Tokyo. In press.

Singh. B. and Saxena, S. N. (1964). Fournal of the Association of Physicians of India, 12, 831 .

Woodward. T. E., Smadel, J. E., Ley, H. L.. jun., Green. 'R., and Mankikar, D.' S. (1948). Annals of Internal Medicine, 29, 131 . 